\title{
Proposta de Zoneamento Ambiental para a bacia transfronteiriça do rio Apa
}

Proposal of Environmental Zoning for the transboundary basin of rio Apa

\section{Proposition de Zonage Environnemental pour le bassin transfrontière de rio Apa}

Propuesta de Ordenamiento Ambiental de la cuenca transfronteriza del río Apa

\author{
Edwaldo Henrique Bazana Barbosa* \\ (bazana_barbosa@yahoo.com.br) \\ Arnaldo Yoso Sakamoto** \\ (arnaldosakamoto@gmail.com) \\ Vitor Matheus Bacani** \\ (vitor.bacani@ufms.com)
}

Recebido em 01/12/2015; revisado e aprovado em 06/01/2016; aceito em 16/01/2016

DOI: http:/ /dx.doi.org/10.20435/1984042X2016205

\begin{abstract}
Resumo: O estudo teve como objetivo elaborar uma proposta de zoneamento ambiental, usando geotecnologias para a bacia transfronteiriça do rio Apa, localizada entre os paralelos $22^{\circ} 36^{\prime} 51^{\prime \prime}$ S e $20^{\circ} 57^{\prime} 37^{\prime \prime}$ S e os meridianos $55^{\circ} 52^{\prime} 28^{\prime \prime} \mathrm{W}$ e $57^{\circ} 59^{\prime} 38^{\prime \prime} \mathrm{W}$, com uma área de aproximadamente $15.433,00 \mathrm{~km}^{2}$, na fronteira do Brasil com o Paraguai. Os métodos de investigação incluíram a aplicação da legislação ambiental (especificamente a Lei $n^{\circ} 12.651$, de 25 de maio de 2012 e Ley $n^{\circ}$ 422/73 Florestal) e análise da fragilidade ambiental.

Palavras-chave: zoneamento ambiental; fragilidade ambiental; geotecnologias.

Abstract: The objective of this study was to develop a proposal for environmental zoning, using geotechnologies, for the transboundary basin of rio Apa, located between the parallel $22^{\circ} 36^{\prime} 51^{\prime \prime} \mathrm{S}$ and $20^{\circ} 57^{\prime} 37^{\prime \prime}$ $\mathrm{S}$ and the meridians $55^{\circ} 52^{\prime} 28^{\prime \prime} \mathrm{W} 5759^{\prime} 38^{\prime \prime} \mathrm{W}$, with an area of approximately $15,433.00 \mathrm{sq}$. $\mathrm{km}$, along the border between Brazil and Paraguay. The research methods included the implementation of environmental legislation (specifically the law no. 12,651, may 25, 2012 and law no. 422/73 Forestry) and analysis of environmental fragility.

Key words: environmental zoning; environmental fragility; geotechnologies.

Résumé: L'objectif de cette étude était de développer une proposition de zonage de l'environnement, utilisant geo, pour bassin transfrontière du rio Apa, située entre les parallèle 2236 ' 51» S et 20 57' 37» S et les méridiens $55^{\circ} 52^{\prime} 28 » W 5759^{\prime} 38 » W$, avec une superficie d'environ $15433,00 \mathrm{~km}^{2}$, à la frontière du Brésil et du Paraguay. Les méthodes de recherche inclus la mise en œuvre de la législation sur l'environnement (en particulier la loi no. 12 651 , 25 mai 2012 et la loi n 422/73 Foresterie) et l'analyse de fragilité de l'environnement.

Mots-clés: zonage de l'environnement; fragilité de l'environnement; geotechnologies.

Resumen: El objetivo de este estudio fue desarrollar una propuesta de zonificación ambiental, con geotecnologias, de cuenca transfronteriza del río Apa situado entre los paralelos $22^{\circ} 36^{\prime} 51^{\prime \prime} \mathrm{S}$ y $20^{\circ} 57^{\prime} 37^{\prime \prime} \mathrm{S}$ y los meridianos $55^{\circ} 52^{\prime} 28^{\prime \prime} \mathrm{W}$ y $57^{\circ} 59^{\prime} 38^{\prime \prime} \mathrm{W}$, con una superficie de $15.433,00 \mathrm{~km}^{2}$ aproximadamente, en la frontera entre Brasil y Paraguay. Los métodos de investigación incluyen la aplicación de la legislación ambiental (en particular la Ley no. 12.651 , 25 de mayo de 2012 y Ley no. 422/73 Forestal) y el análisis de fragilidad ambiental. Palabras clave: zonificación ambiental; fragilidad del medio ambiente; geotecnologias.
\end{abstract}

\section{INTRODUÇÃO}

Atualmente é imprescindível uma metodologia conservacionista e preservacionista para análise e investigação da situação real da paisagem em um dado espaço geográfico.

Considerando a totalidade da paisagem, representada pelos elementos físicos, biológicos e pelas relações sociais, observa-se que as preocupações em torno das questões ambientais estão cada vez mais em evidência, pois o meio natural constitui-se como palco das relações humanas. Os avanços tecnológicos propiciaram um significativo aumento da rede urbana e o crescimento da produção agropecuária, a fim de atender as necessidades de consumo de uma sociedade. Portanto devem-se planejar as ações de crescimento econômico e contornar os agentes agressivos dos processos de exploração irracional.

O planejamento físico-territorial consiste na concepção do planejamento como atividade de elaboração de planos de orde-

\footnotetext{
* Universidade Federal de Mato Grosso do Sul (UFMS), Campus de Aquidauana, Mato Grosso do Sul, Brasil.

** Universidade Federal de Mato Grosso do Sul (UFMS), Campus de Três Lagoas, Mato Grosso do Sul, Brasil.
} 
namento espacial (zoneamento), funcionando o plano como um conjunto de diretrizes a serem seguidas e metas a serem perseguidas - quanto aos usos da terra, ao controle da expansão da produção, à provisão de áreas de preservação permanente etc. (TAYLOR, 1998 apud SOUZA, 2004).

A bacia hidrográfica é uma unidade de planejamento fundamental da superfície terrestre, considerada como principal unidade fisiográfica do terreno, porque suas características governam todo o fluxo superficial da água. Constitui, portanto, uma área ideal para o planejamento integrado do manejo dos recursos naturais no meio ambiente por ela definido, conforme a prerrogativa legislativa, conforme a Lei $n^{\circ}$ 9.433/97 que institui a
Política Nacional de Recursos Hídricos e Ley $n^{\circ}$ 3.239/07 de los Recursos Hidricos Del Paraguay (PARAGUAY, 2007a).

$A$ área de análise é a bacia hidrográfica transfronteiriça do rio Apa, localizada entre os paralelos $22^{\circ} 36^{\prime} 51^{\prime \prime}$ S e $20^{\circ} 57^{\prime} 37^{\prime \prime} \mathrm{S}$ e os meridianos $55^{\circ} 52^{\prime} 28^{\prime \prime} \mathrm{W}$ e $57^{\circ} 59^{\prime} 38^{\prime \prime} \mathrm{W}$. Os municípios que integram a bacia do rio Apa em território brasileiro, no Estado de Mato Grosso do Sul são: Ponta Porã, Antônio João, Bela Vista, Caracol, Porto Murtinho, Bonito e Jardim. Em território paraguaio, a área da bacia inclui os Departamentos de Concepción e Amambay, contemplando os seguintes municípios: Bella Vista, Concepción, Pedro Juan Caballero, San Carlos e San Lázaro, conforme a Figura 1.
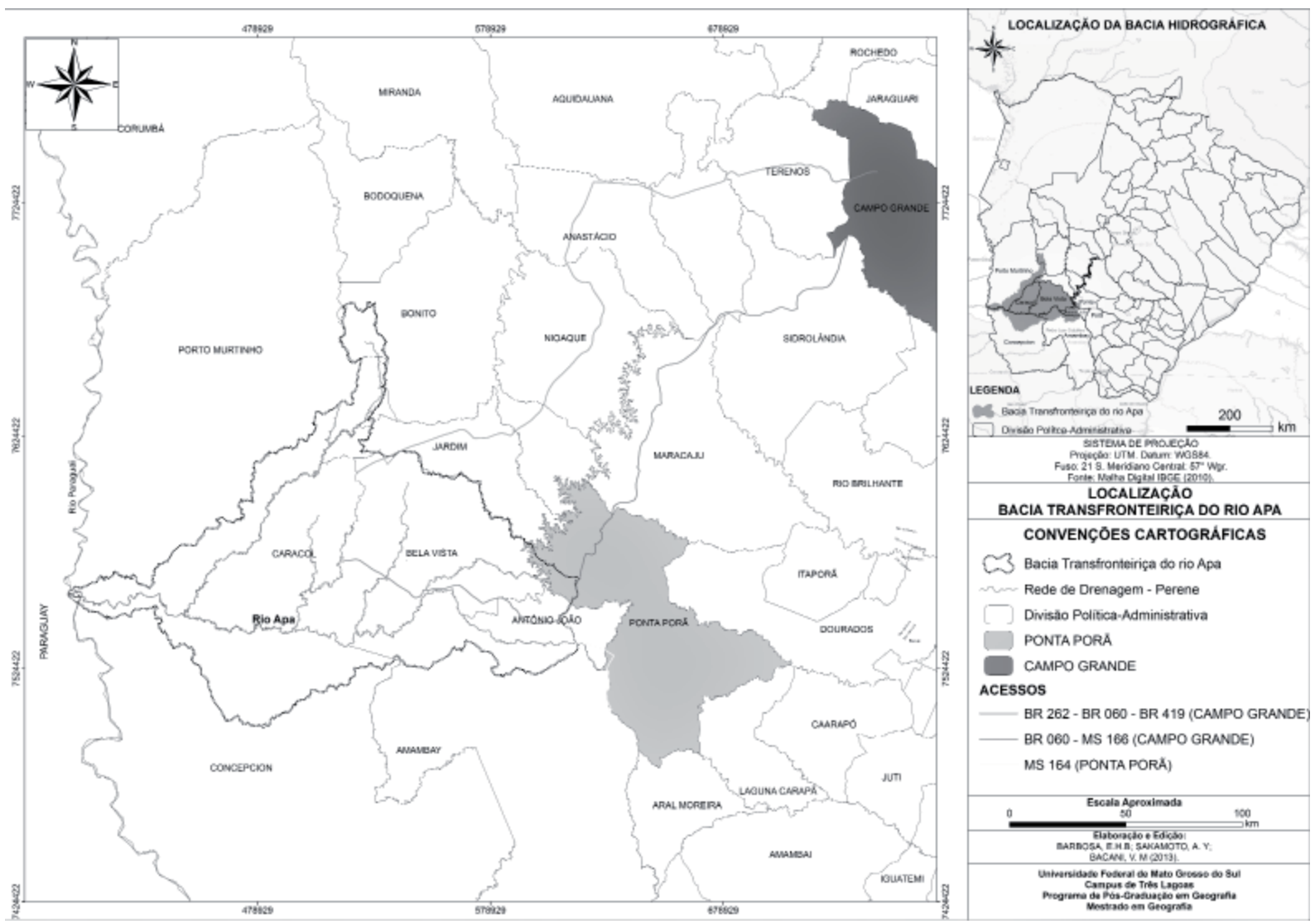

Figura 1 - Localização da bacia transfronteiriça do rio Apa.

Portanto o objetivo deste trabalho foi elaborar uma proposta de zoneamento ambiental para bacia hidrográfica transfronteiriça do rio Apa, através de dados de sensoriamento remoto e técnicas de geoprocessamento, em um ambiente de Sistema de Informação Geográfica (SIG). A síntese das análises é expressa através da cartografia temática.

\section{METODOLOGIA}

Os procedimentos metodológicos para a formulação do zoneamento ambiental para a bacia transfronteiriça do rio Apa apoiaram-se na adaptação metodológica das propostas de Crepani et al. (2001) e Ross (1994).

Os produtos cartográficos empregados na análise da fragilidade ambiental 
foram: Solos, Intensidade Pluviométrica, Clinográfico, Importância Biológica e o Uso da Terra e Cobertura Vegetal do ano de 2012.

Para a elaboração do mapa de solos, foram utilizados os dados secundários, em formato shapefile, de Gorostiaga et al. (1995) e Mato Grosso do Sul (1985).

A variabilidade espacial pluviométrica foi elaborada a partir de médias anuais pluviométricas disponíveis entre os anos de 1970 a 2007, de estações meteorológicas da Agência Nacional das Águas (ANA) e dos boletins da Unidad de Gestión de Riesgos (UGR) del Ministerio de Agricultura y Ganadería (MAG), do ano de 2007 (PARAGUAY, 2007b).

Para espacialização da pluviosidade, foi empregado o método de interpolação, denominado Krigagem, que consiste em um método geoestatístico que leva em consideração as características espaciais de autocorrelação de variáveis regionalizadas (LANDIM, 2000).

O mapa clinográfico apoiou-se na proposta de De Biase (1992), foi utilizada a imagem de RADAR interferométrico SRTM (Shuttle Radar Topography Mission), com 30 metros de resolução espacial, submetida ao comando Focal Statistics, que, nesse caso, se trata de um filtro de médias com $3 \times 3$ células de dimensão. Em seguida, o SRTM “filtrado" é conduzido ao comando Fill, que remove as depressões espúrias. Ambos os procedimentos foram realizados na extensão Spatinal Analist Tools, do ArcGis 10.0® (ARCGIS/ ARCINFO, 2012). Para essa análise, foram definidas cinco classes, conforme proposta descrita em Ross (1994).
Os dados das áreas de importância biológica foram extraídos do banco de dados do Ministério do Meio Ambiente (MMA), no formato shapefile e, posteriormente, a edição vetorial para recorte da área de estudo (Arctoolbox/Analysis tolls/Extract).

Para a geração do mapa de uso da terra e cobertura vegetal do ano de 2012, foi utilizado mosaico de imagens do satélite IRS-P6 (RESOURCESAT-1), sensor LISS-III - (Linear Imaging Self-Scanner), órbita ponto: 320/093, 320/094, 321/093, 321/094, 322/093, 322/094; datadas em julho de 2012, sendo usadas as bandas 3B, 4R e 5G para a composição colorida. Para o registro das imagens, utilizaram-se pontos de controle baseando-se no mosaico de imagens georreferenciadas do satélite LANDSAT-5, sensor TM (Thematic Mapper), datada em maio de 2006.

Os mosaicos de imagens de satélites foram realizados através do processo de equalização automática com linha de corte, através do algoritmo de Correspondência de Histograma (Histogram Match), no ArcGis 10.1®.

Em todas as imagens, foram aplicadas o contraste linear e, posteriormente, submetidas à classificação supervisionada por regiões. Em seguida, avaliada, em cada região, a distância de Bhattacharya entre as classes, conforme Equação 1 (MOREIRA, 2005). A etapa de segmentação pautou-se na utilização do método de crescimento de regiões. Por meio do método exploratório, definiram-se os limiares de similaridade e área (pixels), os quais correspondem aos valores 5 e 20 respectivamente.

$$
B(p i, p j)=1 / 2(m 1-m 2)^{T} \sum(m i-m j)+1 / 2 \ln \frac{\left|\sum(m i-m j)\right|}{\left.\left|\sum i^{1 / 2}\right| \sum j\right|^{1 / 2}}
$$

Onde: $\mathrm{B}=$ distância de Bhattacharya; $P i$ e $p j$ = pixels nas classes i e j; $m i$ e $m j=$ médias das classes i e j; $\mathrm{T}=$ matriz transposta; $\ln =\log$ aritmo neperiano; $i$ e $j=$ classes dentro do contexto.

A validação da classificação pautou-se na confrontação de 100 amostras de campo (realizado em 01/06/2012), com distribuição dos valores entre as classes, no mapa temático classificado, segundo os parâmetros estatísticos: índice de concordância Kappa (Equação 2) e acurácia global (Equação 3).

$$
\begin{gathered}
\hat{K}=\frac{N \sum_{i=1}^{k} x_{\bar{u}}-\sum_{i=1}^{k}\left(x_{i+} \cdot x_{+i}\right)}{N^{2}-\sum_{i=1}^{k}\left(x_{i+} \cdot x_{+i}\right)} \\
\text { Acurácia }_{\text {global }}=\left(\frac{\sum_{i=1}^{k} x_{i}}{N}\right)
\end{gathered}
$$


Onde:

$\hat{K}$ : valor estimado Kappa;

$k$ : número de linhas;

$\sum_{i=1}^{k} x_{i}$ : número de observações na linha $i$ e coluna $i$;

$\sum_{i=1}^{k} x_{i i}: \begin{gathered}\text { soma dos elementos da matriz } \\ \text { em sua diagonal principal; }\end{gathered}$

$X_{+i}$ : soma total das observações para as linhas;

$X_{+i}$ : soma total das observações para as colunas;

$N$ : número de observações total.

Após o emprego do algoritmo de classificação, o produto temático passou pelo processo de avaliação do desempenho do classificador, com que se alcançaram dados obtidos de campo (pontos de GPS) para confrontação do mapeamento com os dados avistados a campo. As correções foram realizadas através da edição matricial.

Para a elaboração do mapa de fragilidade ambiental, inicialmente foi feita a conversão dos dados vetoriais para a estrutura matricial (formato Grid.) e, posteriormente, a reclassificação, por meio da ferramenta Reclassify. Posteriormente os dados foram submetidos aos métodos de combinação de mapas, sobreposição ponderada. Para os procedimentos de reclassificação e sobreposição ponderada, utilizou-se a extensão Spatial Analyst Tools no ArcGIS 10®.
Seguindo o proposto por Ross (1994), atribuiu-se pesos ao mapa clinográfico e ao mapa de solos, atribuindo valores às classes mapeadas. De acordo com o proposto por Crepani et al. (2001), a atribuição de pesos (valores) foram nas classes de intensidades pluviométricas. "A partir dos valores obtidos de intensidades pluviométricas e suas relações com a vulnerabilidade à perda de solo, foi elaborada uma adaptação metodológica com base numa regra de três simples entre os valores máximo de vulnerabilidade à perda de solo" (CREPANI et al., 2001) e os graus de fragilidade definido por Ross (1994), na qual obteve-se o grau de fragilidade e o peso, conforme a Equação 4.

$\mathrm{IP}=\mathrm{PMA} / \mathrm{DPC}$

Onde: IP = Intensidade Pluviométrica; PMA = Precipitação Média Anual; DPC = Duração do Período Chuvoso

Assim, as relações entre as classes mapeadas e os pesos são exemplificados na Tabela 1 e no Quadro 1.

Tabela 1 - Relação entre as unidades de relevo e os graus de fragilidade.

\begin{tabular}{ccc}
\hline Graus de fragilidade & Clinografia & Pesos \\
\hline Muito Fraca & até 6\% & 1 \\
Fraca & de $6 \%$ a $12 \%$ & 2 \\
Média & de $12 \%$ a $20 \%$ & 3 \\
Forte & de $20 \%$ a $30 \%$ & 4 \\
Muito Forte & acima de 30\% & 5 \\
\hline
\end{tabular}

Fonte: Ross (1994). 


\begin{tabular}{|c|c|c|}
\hline $\begin{array}{l}\text { Graus de } \\
\text { fragilidade }\end{array}$ & $\begin{array}{c}\text { Tipos de Solos } \\
\text { Macrozoneamento (1985) }\end{array}$ & Pesos \\
\hline Média & Argissolo Vermelho-Amarelo com textura argilosa & 3 \\
\hline Forte & Argissolo Vermelho-Amarelo com textura média & 4 \\
\hline Média & Argissolo Vermelho-Amarelo com textura média e média/argilosa & 3 \\
\hline Média & Argissolo Vermelho-Amarelo Eutrófico com textura argilosa & 3 \\
\hline Muito Forte & Argissolo Vermelho-Amarelo Eutrófico com textura argilosa cascalhenta & 5 \\
\hline Forte & $\begin{array}{c}\text { Argissolo Vermelho-Amarelo Eutrófico com textura argilosa e média cascal- } \\
\text { henta/argilosa cascalhenta }\end{array}$ & 4 \\
\hline Média & Argissolo Vermelho-Amarelo Eutrófico com textura média/argilosa & 3 \\
\hline Média & $\begin{array}{c}\text { Argissolo Vermelho-Amarelo Eutrófico com textura média/argilosa e areno- } \\
\text { sa/média }\end{array}$ & 3 \\
\hline Média & Argissolo Vermelho-Amarelo Eutrófico com textura muito argilosa & 3 \\
\hline Média & Argissolo Vermelho-Amarelo Eutrófico com textura muito argilosa e argilosa & 3 \\
\hline Média & Chernossolo Rêndzico & 3 \\
\hline Média & Gleissolo Timórfico & 3 \\
\hline Média & Gleissolo Timórfico com textura média/argilosa & 3 \\
\hline Muito Baixa & Latossolo Vermelho Ácrico com textura argilosa & 1 \\
\hline Baixa & Latossolo Vermelho Ácrico com textura argilosa e média & 2 \\
\hline Baixa & Latossolo Vermelho Ácrico com textura média e argilosa & 2 \\
\hline Muito Baixa & Latossolo Vermelho Ácrico com textura muito argilosa & 1 \\
\hline Muito Baixa & Latossolo Vermelho Aluminoférrico com textura muito argilosa & 1 \\
\hline Muito Baixa & Latossolo Vermelho Eutroférrico com textura argilosa e muito argilosa & 1 \\
\hline Muito Baixa & Latossolo Vermelho Eutroférrico com textura argilosa & 1 \\
\hline Muito Alta & Neossolo Litólico com textura arenosa cascalhenta & 5 \\
\hline Muito Alta & Neossolo Litólico com textura arenosa e média cascalhenta & 5 \\
\hline Muito Alta & Neossolo Litólico com textura indiscriminada & 5 \\
\hline Muito Alta & Neossolo Litólico com textura indiscriminada cascalhenta e não cascalhenta & 5 \\
\hline Muito Alta & Neossolo Regolítico com textura arenosa cascalhenta & 5 \\
\hline Muito Alta & Neossolo Regolítico com textura média muito cascalhenta & 5 \\
\hline Média & Planossolo Nátrico com textura arenosa/argilosa & 3 \\
\hline Média & Planossolo Nátrico com textura arenosa/média e média & 3 \\
\hline Média & Plintossolo com textura arenosa/argilosa & 3 \\
\hline Baixa & Vertissolo com textura argilosa & 2 \\
\hline $\begin{array}{l}\text { Graus de } \\
\text { fragilidade }\end{array}$ & Paraguay (1995) & \\
\hline Média & Aquic Eutrochrept con textura Francosa fina & 3 \\
\hline Forte & Aquic Udifluvent con textura Arenosa & 4 \\
\hline Baixa & Calcic Argiudoll con textura Arcillosa fina & 2 \\
\hline Baixa & Humic hapludult con textura Arcilla fina & 2 \\
\hline Baixa & Lithic Hapludoll con textura Arcillosa fina & 2 \\
\hline Baixa & Lithic Udorthent con textura Arcillosa fina & 2 \\
\hline Muito Baixa & Mollic Paleudalf con textura Francosa gruesa & 1 \\
\hline Forte & Typic Dystrochrept con textura Arenosa & 4 \\
\hline Baixa & Typic Hapludert con textura Arcillosa fina & 2 \\
\hline Baixa & Typic hapludult con textura Arcillosa fina & 2 \\
\hline Forte & Typic Quartzipsamment con textura Arenosa & 4 \\
\hline Baixa & Typic Rhodudult con textura Arcillosa fina & 2 \\
\hline Forte & Typic Udipsamment con textura Arenosa & 4 \\
\hline Forte & Umbric Dystrochrept con textura Arenosa & 4 \\
\hline Baixa & Vertic Paleudoll con textura Arcillosa fina & 2 \\
\hline
\end{tabular}

Quadro 1 - Relação entre os graus de fragilidade e os solos.

Fonte: Adaptado Ross (1994) e Paraguay (1995). Quadro 1

Os graus de fragilidade foram atribuídos levando em consideração o nível de importância biológica, conforme a Tabela 2. 
Tabela 2 - Áreas de Importância Biológica e os graus de fragilidade.

\begin{tabular}{ccc}
\hline Importância Biológica & Graus de fragilidade & Pesos \\
\hline Extremamente Alta & Muito Alta & 5 \\
Muito Alta & Alta & 4 \\
Alta & Média & 3 \\
Insuficientemente conhecida & Desconhecida/Nula & 0 \\
\hline
\end{tabular}

Fonte: Probio/MMA.

A metodologia de Ross (1994) possibilita atribuir pesos ao mapa de uso da terra e cobertura vegetal, atribuindo valores às classes mapeadas, conforme a Tabela 3.

Tabela 3 - Uso da terra e cobertura vegetal e os graus de fragilidade.

\begin{tabular}{ccc}
\hline Classes Temáticas & Graus de fragilidade & Pesos \\
\hline Áreas de Cultivo & Alta & 4 \\
Água & Muito Alta & 5 \\
Áreas Úmidas & Muito Alta & 5 \\
Pastagem & Alta & 4 \\
Solo Exposto & Muito Alta & 5 \\
Mata & Baixa & 2 \\
Reflorestamento & Média & 3 \\
Área Urbana & Muito Alta & 5 \\
\hline
\end{tabular}

Os mapas de análise resultantes são respectivamente: potencial natural à erosão (que indica a fragilidade potencial) e a fragilidade ambiental (indica a fragilidade emergente).

O mapeamento consiste na definição de áreas com graus diferenciados de proteção, com diretrizes relativas ao uso e ocupação dos recursos naturais. Para isto, serão utilizadas as diretrizes apresentadas pelo PCBAP (BRASIL, 1997), determinações impostas pela legislação ambiental, notadamente o Código Florestal- Lei n. 12.651, de 25 de maio de 2012 (BRASIL, 2012) e Unidades de Conservação criadas no interior da bacia hidrográfica, os graus de fragilidade e CIDEMA (2003).

\section{RESULTADOS E DISCUSSÃO}

O potencial natural à erosão é um produto que antecipa a análise da fragilidade ambiental. Esse produto cartográfico indica áreas onde os processos erosivos são naturais, devido ao tipo de solo, à intensidade pluviométrica, às características topográficas e à importância biológica do ambiente, conforme apresentado na Figura 2. 


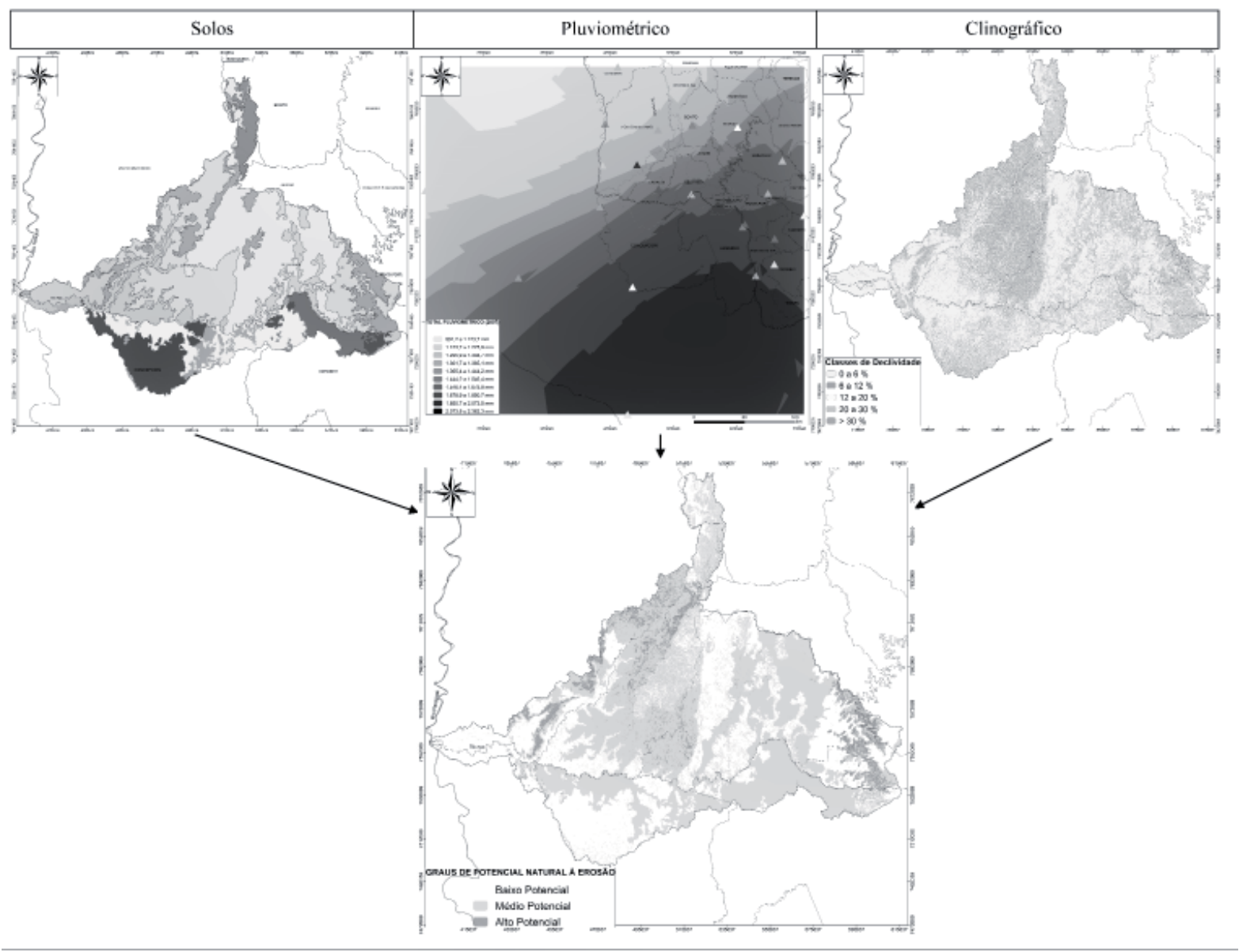

Figura 2 - Mapa de Potencial Natural à Erosão da bacia transfronteiriça do rio Apa.

Os dados de importância biológica foram atribuídos no mapeamento, porém os valores recobriram parcialmente a área da bacia, o que diminuiu o grau de fragilidade, formado por valores "zero".

A distribuição por área das classes de Potencial Natural a Erosão dos solos é descrita na Tabela 4.

Tabela 4 - Distribuição das classes de Potencial Natural à Erosão

\begin{tabular}{ccc}
\hline Classes & Área $\left.\mathbf{( k m}^{2}\right)$ & Área $\mathbf{( \% )}$ \\
Baixa & $6.132,29$ & 39,74 \\
Média & $7.254,12$ & 47,00 \\
Alta & $2.046,32$ & 13,26 \\
Total & $\mathbf{1 5 . 4 3 2 , 7 2}$ & $\mathbf{1 0 0 , 0 0}$ \\
\hline
\end{tabular}

A classe Baixa encontra-se em 39,74\% da área de estudo associada a relevo suave com formas aplainadas que não ultrapassam inclinações de $20 \%$, com variação altimé- trica de 90 a $690 \mathrm{~m}$, em que desenvolvem Latossolos de textura argilosa, Argissolo Vermelho-Amarelo com textura argilosa a arenosa e Vertissolo com textura argilosa. As chuvas são concentradas nessas áreas e variam de $1.376,8$ a $1.578,7 \mathrm{~mm}$ anual.

Nota-se que $47,00 \%$ da bacia analisada são consideradas como Média a fragilidade potencial à erosão, localizada na região central da bacia, limitando-se ao norte com a Serra da Bodoquena, ao sul com rio Apa, a leste com o rio Caracol e a oeste o limite da bacia, próximo ao rio Perdido.

$\mathrm{Na}$ área considerada como Média, os solos predominantes são: Argissolo Vermelho-Amarelo com textura argilosa a cascalhenta, Planossolo Nátrico com textura arenosa/média e média, Neossolo Regolítico com textura média muito cascalhenta e Chernossolo Rêndzico. São solos característicos de declividade que varia de 6 a $30 \%$. A pluviosidade nessa área varia de $1.246,5 \mathrm{a}$ 1.578,7 mm anual. A importância biológica 
dessa área varia de Alta a Extremamente Alta, devido à presença do Parque Nacional da Serra da Bodoquena.

A Alta fragilidade corresponde a $2.046,32 \mathrm{~km}^{2}$, sendo a menor representação na bacia, com aproximadamente $13,26 \%$, apresenta inclinações maiores que $30 \%$ associadas a Neossolos Litólicos e Regolítico com textura arenosa média/cascalhenta a muito cascalhenta, região de extrema importância biológica.
Assim, a bacia do rio Apa apresenta 60,26 \% de potencial natural à erosão que varia de alto a muito alto, justamente em áreas sustentadas por relevo dissecado e solos com características arenosas e cascalhentas.

A combinação do mapa de potencial natural à erosão dos solos com o mapa de análise de uso da terra e cobertura vegetal do ano de 2012 resultou em um mapa de síntese, denominado fragilidade ambiental, conforme apresentado na Figura 3.

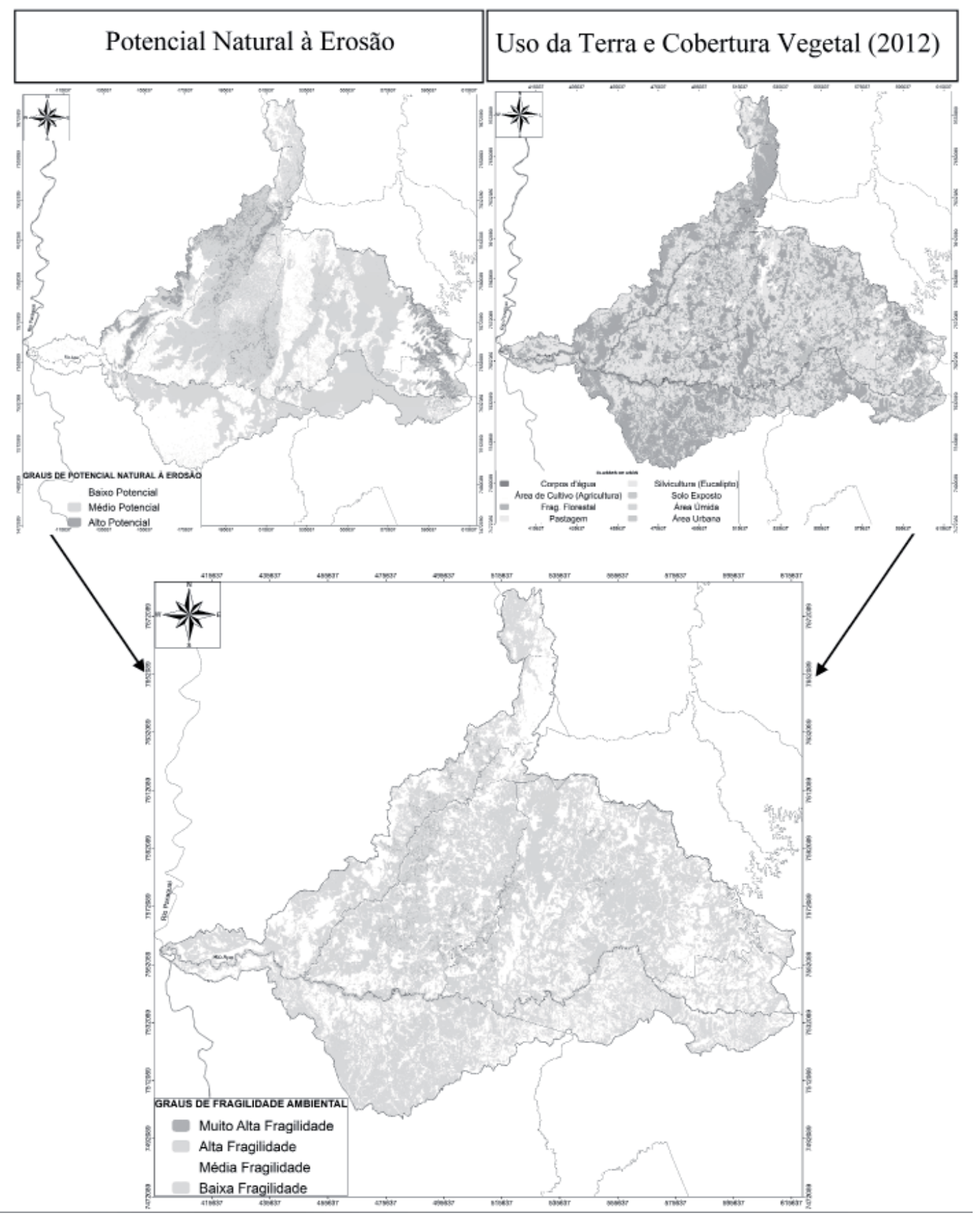

Figura 3 - Mapa de Fragilidade Ambiental da bacia transfronteiriça do rio Apa. 
A Tabela 5 indica que o mapeamento temático do uso da terra e cobertura vegetal do rio Apa realizado com o classificador
Battacharya apresentou uma qualidade muito boa para o ano de 2012.

Tabela 5 - Validação Kappa e Exatidão Global do ano de 2012 da bacia do transfronteiriça do rio Apa, Brasil, 2014.

\begin{tabular}{cccc}
\hline Classificador & Índice Kappa & Exatidão Global & Qualidade* \\
Battacharya & 0,73 & 0,76 & Muito Boa \\
\hline
\end{tabular}

*Conforme Landis e Koch (1977).

A Tabela 6 apresenta a quantificação da distribuição das classes de fragilidade ambiental encontrada na bacia transfronteiriça do rio Apa.

Tabela 6 - Distribuição das áreas de Fragilidade Natural

\begin{tabular}{ccc} 
Classes & Área $\left.\mathbf{( k m}^{\mathbf{2}}\right)$ & Área $\mathbf{( \% )}$ \\
Baixa & $2.584,51$ & 16,75 \\
Média & $7.293,46$ & 47,26 \\
Alta & $5.469,74$ & 35,44 \\
Muito Alta & 85,01 & 0,55 \\
Total & $\mathbf{1 5 . 4 3 2 , 7 2}$ & $\mathbf{1 0 0 , 0 0}$ \\
\hline
\end{tabular}

A Baixa fragilidade ambiental está situada em 145,64 km de extensão do médio curso do rio Perdido até a foz com o rio Apa, as margens do rio Apa até a confluência com o rio Pirarucu e no lado paraguaio da bacia ocupa $46,19 \%$ da área total. Esse resultado é relacionado à baixa fragilidade potencial e à presença da vegetação natural, que tem o papel de proteger o solo localizado nas matas ciliares.

A Média fragilidade ambiental é predominante na bacia transfronteiriça do rio, ocupando uma área de $7.293,46 \mathrm{~km}^{2}$, o que representa $47,26 \%$ do total da área da bacia. Essa classe está espacializada na área destinada à pastagem e nas áreas definidas como áreas úmidas.

A Alta Fragilidade ambiental apresenta a segunda maior distribuição espacial com $5.469,74 \mathrm{~km}^{2}(35,44 \%$ da área da bacia), e está relacionada diretamente com ação antrópica causada pelo desmatamento da vegetação natural para introdução de pastagem para atividade da agropecuária e agricultura, uma vez que grande parte dessa área está em uma região classificada como extremamente Alta pelo mapa da importância biológica.

Ao tratar-se do uso, ocupação e produção na bacia, observa-se que, nas Unidades de Conservação, predominam Altas Fragilidades, devido à falta de manejo adequado nas áreas de pastagem, ocasionando processos erosivos e contribuindo com o assoreamento dos mananciais da bacia. Nessas áreas com a predominância de solos com textura arenosa, devem-se adotar técnicas conservacionistas para minimizar os problemas de erosão hídrica. Assim, sugere-se o método de integração Lavoura-Pecuária, integração essa que resulta em adição de matéria orgânica no solo, melhoria da estrutura, aumento da infiltração da água, aumento da capacidade de produção do solo e diminuição da velocidade de escoamento das enxurradas.

As áreas consideradas Muita Alta correspondem a uma área de $85,01 \mathrm{~km}^{2}$. É caracterizada pela relação entre as classes água, áreas úmidas, área urbana e solo exposto com muito alta fragilidade potencial à erosão, uma vez que esses fatores estão associados a altas declividades, correspondentes acima de $30 \%$, passíveis a processos erosivos comprometendo os recursos hídricos e edáficos.

Após a determinação das áreas de fragilidade ambiental, é necessária a implantação de condicionantes ambientais com fins conservacionistas para minimizar os impactos negativos causados pela ação antrópica.

Assim sendo, é apresentado o Prognóstico Ambiental que define as zonas ambientais e define as recomendações para a Proposta de Zoneamento Ambiental da bacia transfronteiriça do rio Apa, descrita no Quadro 2. 


\begin{tabular}{|c|c|c|c|}
\hline Zona & Categoria & Critérios & Recomendações \\
\hline \multirow{4}{*}{$\begin{array}{l}\text { Zona de } \\
\text { Restrição } \\
\text { Legal - ZRL }\end{array}$} & APPs & Legislação Ambiental & \multirow[b]{2}{*}{$\begin{array}{l}\text { - Isolamento da área de APP, impedindo } \\
\text { o acesso de animais e outras atividades } \\
\text { de produção e/ou ocupação; } \\
\text { - Plantio de vegetação típica de espécies } \\
\text { arbóreas nativas do cerrado ao redor } \\
\text { dos cursos hídricos; } \\
\text { - Manter os remanescentes florestais, } \\
\text { salvo os casos previstos em lei específica. }\end{array}$} \\
\hline & $\begin{array}{l}\text { Parque Natural } \\
\text { Municipal } \\
\text { Parque Nacional }\end{array}$ & $\begin{array}{l}\text { Unidades de } \\
\text { Conservação de } \\
\text { Proteção Integral }\end{array}$ & \\
\hline & $\begin{array}{c}\text { Areas silvestres } \\
\text { protegidas }\end{array}$ & Ley $n^{\circ} 422 / 73$ Florestal & $\begin{array}{l}\text { - Atender o Art. } 42 \text { de La Ley } n^{0} 422 / 73 \\
\text { Florestal. }\end{array}$ \\
\hline & $\begin{array}{l}\text { Remanescentes } \\
\text { Florestais }\end{array}$ & Fragmentos Florestais & $\begin{array}{l}\text { - Supressão vegetal permitida nos casos } \\
\text { previstos em lei especifica e mediante } \\
\text { a averbação da respectiva reserva legal } \\
\text { na propriedade. }\end{array}$ \\
\hline $\begin{array}{c}\text { Zona de } \\
\text { Ocupação } \\
\text { Restrita - ZOR }\end{array}$ & Topo de Morros & Legislação Ambiental. & $\begin{array}{l}\text { - Isolamento da área, impedindo o } \\
\text { acesso de animais e outras atividades } \\
\text { de produção e/ou ocupação. }\end{array}$ \\
\hline $\begin{array}{l}\text { Zona } \\
\text { Urbanizada } \\
- \text { ZU }\end{array}$ & Área Urbanizada & $\begin{array}{l}\text { Área construída } \\
\text { homogênea. }\end{array}$ & $\begin{array}{l}\text { - Determinar aárea dealagamento (planície } \\
\text { de inundação), proibindo a ocupação } \\
\text { nesta área e desenvolver projetos de } \\
\text { educação ambiental com os moradores. } \\
\text { - Elaborar Planos Diretores e/ ou revisar o } \\
\text { existente (município de Bela Vista, MS). }\end{array}$ \\
\hline $\begin{array}{c}\text { Zona de } \\
\text { Incongruência } \\
-\mathrm{ZI} \\
\end{array}$ & $\begin{array}{c}\text { Conflito entre o uso } \\
\text { da terra e legislação } \\
\text { ambiental }\end{array}$ & $\begin{array}{l}\text { Combinação de } \\
\text { APPs com áreas } \\
\text { antropizadas }\end{array}$ & $\begin{array}{l}\text { - Recuperação de mata ciliar, observando } \\
\text { a Lei } n^{\circ} 12.651 \text { de } 25 \text { de Maio de } 2012 \text {. }\end{array}$ \\
\hline \multirow{2}{*}{$\begin{array}{c}\text { Zona de } \\
\text { Unidades de } \\
\text { Conservação - } \\
\text { ZUC }\end{array}$} & $\begin{array}{l}\text { Área de Proteção } \\
\text { Ambiental - APA }\end{array}$ & Decreto Municipal & \multirow{2}{*}{$\begin{array}{l}\text { Atender o disposto nos respectivos } \\
\text { Plano de Manejos (aprovados pelo } \\
\text { poder público). }\end{array}$} \\
\hline & \begin{tabular}{|c|} 
Reserva Natural do \\
Patrimônio Particular \\
Natural - RPPN \\
\end{tabular} & Portaria & \\
\hline \multirow{2}{*}{$\begin{array}{c}\text { Zona } \\
\text { Produtiva } \\
\text { Rural - ZPR }\end{array}$} & Alta Restrição & $\begin{array}{l}\text { - Declividade ente } 20 \text { a } \\
30 \% \text {. } \\
\text { - Argissolo Vermelho- } \\
\text { Amarelos. } \\
\text { - Áreas de pastagem. } \\
\end{array}$ & $\begin{array}{l}\text { - Determinação de curvas de nível e } \\
\text { terraceamento. } \\
\text { - Uso indicado: pecuária com altas } \\
\text { limitações e reflorestamento. }\end{array}$ \\
\hline & Média Restrição & $\begin{array}{l}\text { - Declividade entre } 6 \text { a } \\
20 \% \text {. } \\
\text { - Argissolo Vermelho- } \\
\text { Amarelos. } \\
\text { - Áreas de pastagem } \\
\end{array}$ & $\begin{array}{l}\text { - Incentivo à agricultura familiar. Uso } \\
\text { agropecuário com criação intensiva. } \\
\text { - Manter os fragmentos florestais. }\end{array}$ \\
\hline $\begin{array}{c}\text { Zona de } \\
\text { Assentamento } \\
\text { Rural - ZAR }\end{array}$ & $\begin{array}{l}\text { Assentamento da } \\
\text { Reforma Agrária }\end{array}$ & Agricultura Familiar & $\begin{array}{l}\text { - Incentivo à agricultura familiar; } \\
\text { - Poder Público oferecer Extensão Rural, } \\
\text { através dos órgãos competentes; } \\
\text { - Uso agropecuário com criação intensiva; } \\
\text { - Manter os fragmentos florestais. } \\
\text { - Recuperar a mata ciliar, observando o } \\
\text { disposto na Lei no } 12.651 \text { de25 de Maio } \\
\text { de } 2012 \text {. }\end{array}$ \\
\hline $\begin{array}{c}\text { Zona de } \\
\text { Terras } \\
\text { Indígenas - } \\
\text { ZTI }\end{array}$ & Terras Indígenas & $\begin{array}{l}\text { Registro SPU. } \\
\text { Decreto de } \\
\text { Homologação } \\
\text { publicado. }\end{array}$ & $\begin{array}{l}\text { - Incentivo a agricultura familiar; } \\
\text { - Poder Público oferecer Extensão Rural, } \\
\text { através dos órgãos competentes; } \\
\text { - Uso agropecuário com criação intensiva; } \\
\text { - Manter os fragmentos florestais. } \\
\text { - Recuperar a mata ciliar, observando o } \\
\text { disposto na Lei no } 12.651 \text { de } 25 \text { de Maio } \\
\text { de } 2012 \text {. }\end{array}$ \\
\hline
\end{tabular}

Quadro 2 - Prognóstico Ambiental 
A síntese do prognóstico ambiental é o zoneamento ambiental preliminar, representado na Figura 4.

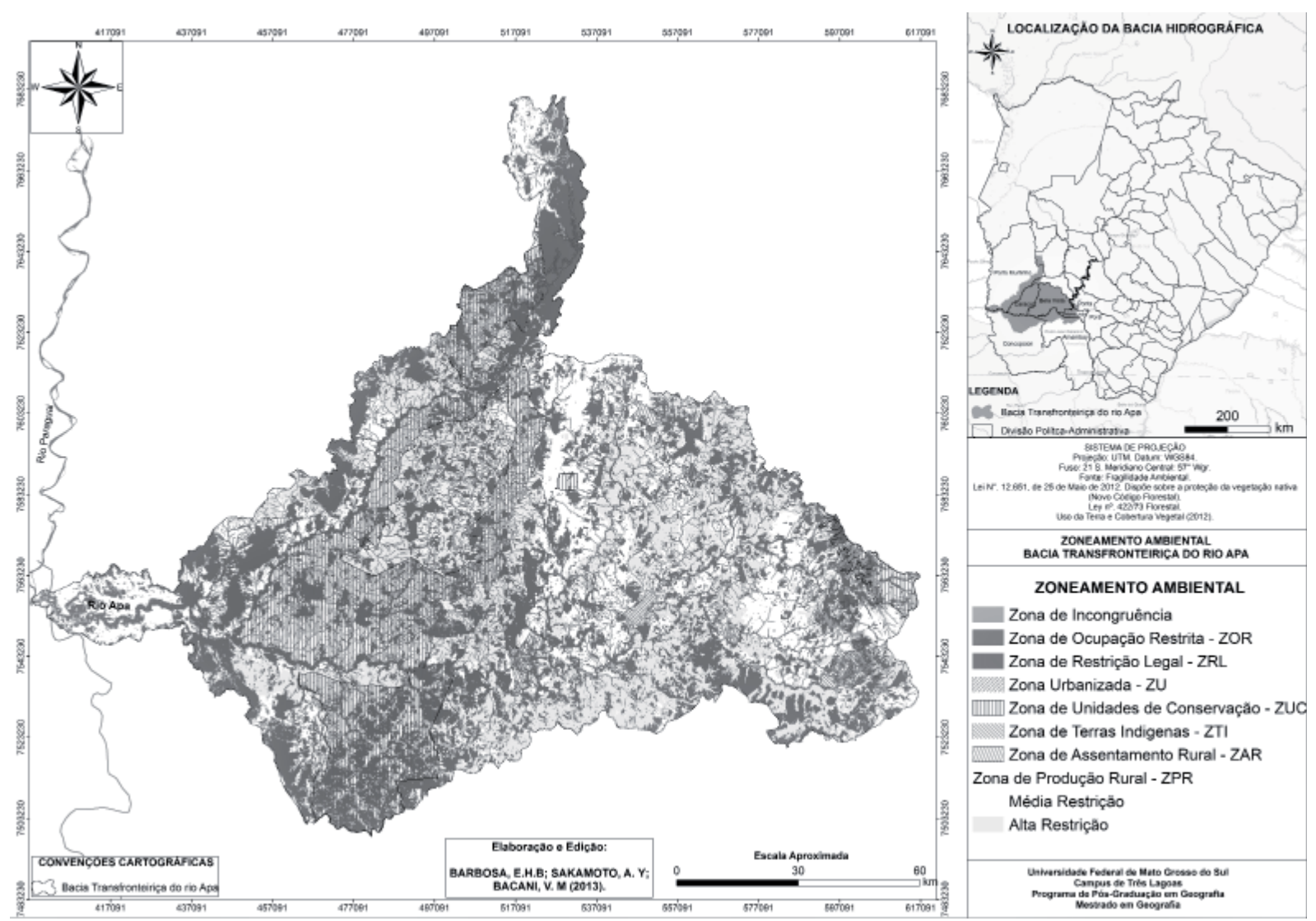

Figura 4 - Mapa do Zoneamento Ambiental da bacia transfronteiriça do rio Apa.

Além das diretrizes apresentadas no Prognóstico Ambiental, serão consideradas as prioridades, determinadas nas Áreas Prioritárias para a Conservação, Utilização Sustentável e Repartição de Benefícios da Biodiversidade Brasileira (BRASIL, 2007), tendo em vista o disposto nos decretos n. 2.519 de 16 de março de 1998 e 5.092, de 21 de maio de 2004. Assim definem-se as seguintes áreas: a) Criação do Corredor Serra do Maracaju: recuperar as nascentes e formular a Criação de Unidade de Conservação de Proteção Integral e de Uso Sustentável, pois existe um forte processo de assoreamento dos rios; carvoarias; agropecuária; plantações de cana-de-açúcar; manejo inadequado de APPs.

b) Planalto da Bodoquena: incentivar criação de RPPNs, pois a área é divisor de águas da Serra da Bodoquena; área de recarga dos aquíferos locais; área de borda com a região do Pantanal. c) Foz do Apa: recuperar as Matas Ciliares do Rio Apa. Devido à presença de manchas de Chaco seco (espinheiro), Região de concentração de Carandás e Paratudo e por ser um complexo de paisagem de influência de Chaco, Cerrado e Florestas secas Semidecíduas (estacionais), faz-se necessária a criação de UC, do tipo Parque Natural.

A recuperação da mata ciliar nas APPs e Topos de Morros deverá ser submetida ao processo de Enriquecimento Florestal, conforme a metodologia proposta por Durigan et al. (2011). A escolha das espécies deverá ser baseada no trabalho elaborado por Pott e Pott (2003).

A supressão vegetal das áreas indicadas como "Fragmentos Florestais" deverá possuir averbação de Reserva Legal na propriedade rural e o previsto na Resolução Estadual SEMAC/MS n. 18 de 5 de agosto de 2008.

Ao analisar as questões urbanas, somente o município de Bela Vista possui Plano 
Diretor - Lei Municipal Complementar $\mathrm{n}^{\circ}$ 019/2006, de 10 de outubro de 2006. Do Plano de Bela Vista, até o presente momento, não consta publicada a revisão. Os outros municípios deverão elaborar seus respectivos Planos, a fim de dimensionar a expansão urbana dos respectivos municípios.

Em linhas gerais, o prognóstico ambiental subsidiou a elaboração do zoneamento ambiental para a bacia transfronteiriça do Apa.

\section{CONSIDERAÇÕES FINAIS}

O levantamento dos aspectos físicos aliado com os dados de sensoriamento remoto e técnicas de geoprocessamento, em um ambiente de Sistema de Informação Geográfica, colaboraram na obtenção e tabulação de todos os elementos físicos da área de análise.

Para o ordenamento da ocupação antrópica, as questões de cunho jurídico deverão ser unificadas. Com isso, o poder público deve priorizar as questões ambientais e principalmente atender os preceitos legislativos, executando ações coercitivas para garantir o equilíbrio e manutenção do meio ambiente natural.

A sugestão para a determinação de políticas pública de conservação inicia-se pela consolidação de um comitê de bacia hidrográfica transfronteiriças ou comissões bilaterais mistas. Existe um avanço nesse sentido, em que a Moção ${ }^{\circ}{ }^{14}$, publicada no Diário Oficial da União em 10 de Março de 2003 (BRASIL, 2003), aprova que o Ministério das Relações Exteriores inicie entendimentos com o governo paraguaio no sentido de desenvolver uma agenda de trabalho, para promover a gestão compartilhada da Bacia do Rio Apa. Assim, deve-se efetivar a proposta e iniciar os trabalhos que visem à gestão compartilhada.

Ao se tratar de recursos transfronteiriços, nota-se que as leis ou normativas são diferentes; no caso da bacia transfronteiriça do rio Apa, fica evidente a disparidade do Código Florestal Brasileiro - Lei $n^{0} 12.651$, de 25 de maio de 2012 (BRASIL, 2012) com a Lei Florestal Paraguaia - Ley $n^{\circ}$ 422/73 (PARAGUAY, 1973). Propõe-se a unificação ou reformação de uma legislação específica para a bacia do rio Apa, seria o início da gestão compartilhada, pois qualquer ação de plane- jamento e gestão deve ter um balizamento legislativo.

Caso se concretize essa ação entre dois governos, ocorrerá um marco histórico no planejamento e na gestão de bacias hidrográficas transfronteiriças.

Outro fator que evidencia uma gestão compartilhada na bacia do rio Apa é a formação das Unidades de Conservação, que possibilitam a formação de corredor ecológico integrando a conservação nos dois países.

Portanto considera-se este trabalho como uma proposta de zoneamento ambiental para a bacia transfronteiriça do rio Apa. Assim sendo, o diagnóstico ambiental ou físico-conservacionista culmina com o zoneamento e o levantamento de diretrizes para a ocupação racional das terras e a recuperação da degradação ambiental.

\section{REFERÊNCIAS}

ARCGIS/ARCINFO - Esri Inc. ArcGis Version 10. Environmental Systems Research Institute Inc. New York, 2012. 1 Cd Rom.

BRASIL. Plano de conservação da bacia do alto Paraguai: análise integrada e prognóstico da Bacia do Alto Paraguai. Brasília: PNMA, 1997. 369p.

Áreas prioritárias para conservação, uso sustentável e repartição de benefícios da biodiversidade brasileira: atualização - Portaria MMA n. 9, de 23 de janeiro de 2007. Ministério do Meio Ambiente, Secretaria de Biodiversidade e Florestas. Brasília: MMA, 2007.

Lei $\mathrm{n}^{\circ}$ 12.651, de 25 de maio de 2012. Dispõe sobre a proteção da vegetação nativa. Diário Oficial da União, Brasília, DF, 28 maio 2012.

Moção n. 14. Diário Oficial da União, Brasília, DF, 10 mar. 2003.

CIDEMA. Avaliação dos Recursos Hídricos da bacia transfronteiriça do rio Apa - Mato Grosso do Sul. Relatório final. CIDEMA/SRH/MMA. Campo Grande, MS, 2003.

CREPANI, Edison et al. Sensoriamento remoto e geoprocessamento aplicados ao Zoneamento Ecológico-Econômico e ao ordenamento territorial. São José dos Campos, SP: Instituto Nacional de Pesquisas Espaciais, 2001.

DE BIASE, M. A Carta Clinográfica. Os métodos de representação e elaboração. Revista do Departamento de Geografia, (6), p. 45-61, 1992.

DURIGAN, Giselda et. al. Manual para recuperação da vegetação de cerrado. 3. ed. rev. e atual. São Paulo: SMA, 2011.

GOROSTIAGA, Oscar López et al. Estudio de Reconocimiento de suelos, capacidad de uso de la tierra y propuesta de ordenamiento territorial preliminar de la Región Oriental del Paraguay. Proyecto de Racionalización del uso de la tierra. Asunción, Paraguay: SSERNMA/ MAG/Banco Mundial, 1995. 
LANDIM, Paulo M. Barbosa. Introdução aos métodos de estimação espacial para confecção de mapas. DGA, IGCE, UNESP/Rio Claro, Lab. Geomatemática, Texto Didático 02, 20p., 2000. Disponível em: <htpp://www.rc.unesp. br/igce/aplicada/textodi.html>. Acesso em: 22 nov. 2014.

LANDIS, J. Richard; KOCH, Gary. G. The measurement of observer agreement for categorical data. Biometrics 33 (1), p.159-174, 1977.

MATOGROSSO DOSUL. Macrozoneamento Geoambiental do Estado do Mato Grosso do Sul. Campo Grande, 1985.

MOREIRA, Maurício Alves. Fundamentos do sensoriamento remoto e metodologias de aplicação. 2. ed. Viçosa, MG: UFV, 2005. 307 p.

PARAGUAY. Ley n. 422 Florestal. Assuncion, 1973. Disponível em: <http:/ /www.seam.gov.py/legislaciones-ambientales.html>. Acesso em: 18 fev. 2013.

. Ley n. 3.239 de los Recursos Hidricos Del Paraguay. Assuncion, 2007a. Disponível em: <http:/ / www.seam. gov.py/legislaciones-ambientales.html>. Acesso em: 18 fev. 2013.
PARAGUAY. Unidad de Gestión de Riesgos (UGR), Ministerio de Agricultura y Ganadería (MAG). BOLETIN "Unidad de Gestión de Riesgos". Asunción, $2007 \mathrm{~b}$.

POTT, Arnildo; POTT, Vali Joana. Plantas nativas para recuperação de áreas degradadas e reposição de vegetação em Mato Grosso do Sul. Campo Grande, MS: Embrapa Gado de Corte, 2003. (Comunicado Técnico 75).

PREFEITURA MUNICIPAL DE BELA VISTA. Lei Municipal Complementar $n^{\circ}$ 019/2006, de 10 de outubro de 2006.

ROSS, Jurandyr Luciano Sanches. Análise empírica da fragilidade dos ambientes naturais e antropizados. Revista do Departamento de Geografia, (8), p. 63-74, 1994.

SEMAC/MS. Resolução $n^{\circ} 18$ de 05 de Agosto de 2008. Diário Oficial do Estado, Campo Grande, MS, 6 ago. 2008.

SOUZA, Marcelo Lopes de. Mudar a cidade: uma introdução crítica ao planejamento e à gestão urbanos. 3. ed. Rio de Janeiro: Bertrand, 2004. 